\title{
Botulinum toxin A (BT-A) versus low-level laser therapy (LLLT) in chronic migraine treatment: a comparison
}

\author{
Toxina botulínica A (BT-A) versus laser terapia de baixa potência (LLLT) em enxaqueca \\ crônica: Uma triagem comparativa \\ Luana Mazzacoratti Loeb', Rebeca Padrão Amorim', Maria da Graça Naffah Mazzacoratti², Fulvio \\ Alexandre Scorza', Mario Fernando Prieto Peres ${ }^{3}$
}

\begin{abstract}
The aim of this work was to evaluate patients with chronic migraine treated with botulinum toxin A (BT-A) and compare this with low level laser therapy (LLLT), referencing: pain days, pain intensity, intake of drugs/self-medication, anxiety and sleep disorders. Methods: Patients were randomized into two groups: BT-A group $(n=18)$ and LLLT group $(n=18)$. Each patient kept three pain diaries: one before (baseline) (30 days), one during treatment (30 days) and one after the post-treatment phase (30 days). Repeated ANOVA plus the Bonferroni post-test, Student's t test, and factorial analysis were applied, and $p<0.05$ was accepted as significant. Results: Our data showed that both treatments were able to reduce headache days, acute medication intake and decrease the intensity of pain. Anxiety was reduced in the BT-A group, while sleep disturbance was reduced in the LLLT group. Conclusion: Our data showed that both treatments can be used to treat chronic migraine, without notable differences between them.
\end{abstract}

Keywords: Migraine disorders; botulism; low level laser therapy.

\section{RESUMO}

O estudo comparou pacientes com cefaleia crônica (CM) tratados com toxina botulínica A (BT-A) versus terapia a laser de baixa intensidade (LLLT), relativos a: dias de dor, automedicação, nervosismo e distúrbios do sono. Métodos: Os pacientes foram randomizados em dois grupos: Grupo BT-A ( $n=18$ ) e Grupo LLLT ( $n=18$ ). Cada paciente preencheu três diários de dor, sendo um antes do início do tratamento (30 dias), durante o tratamento (30 dias) e um após tratamento (30 dias). ANOVA e pós-teste Bonferroni, teste T de Student e análise fatorial foram utilizados e valores de $p<0,05$ foram considerados significativos. Resultados: Ambos os tratamentos foram capazes de reduzir os dias de dor e a ingestão aguda de medicação. Além disso, a ansiedade foi reduzida no grupo BT-A, enquanto que o distúrbio do sono foi reduzido no grupo LLLT. Conclusão: Nossos resultados mostraram que ambos os tratamentos são eficientes contra CM, sem diferença entre eles.

Palavras-chave: Transtornos de enxaqueca; botulismo; laserterapia de baixa potência.

Chronic migraine (CM) is a neurological disorder characterized by debilitating headaches, affecting $2-3 \%$ of the general population ${ }^{1}$, and is one of the main disorders found in neurological clinical practices. Chronic migraine is a multifactorial condition involving altered modulation and control of afferent pathways that are complex in nature. Overstimulation of the trigeminovascular system is responsible for nociceptor activation, cortical spreading depression, mast cell degranulation, release of inflammatory neurogenic mediators and change in ionic channels ${ }^{2}$. Pain-producing structures of the cranium are regulated by sensory systems located in the thalamus, hypothalamus and brainstem ${ }^{1,3,4}$ and several mechanisms are putative targets for CM therapy.

Chronic migraine management includes acute medication optimization and a preventive pharmacological and non-pharmacological approach ${ }^{5,6}$. Current approved therapies are limited, with poor tolerability, refractory profiles and unfavorable costs $^{7}$. Thus, new CM preventive options are needed.

\footnotetext{
${ }^{1}$ Universidade Federal de São Paulo, Escola Paulista de Medicina, Departamento de Neurologia/Neurocirurgia, São Paulo SP, Brasil;

2 Universidade Federal de São Paulo, Escola Paulista de Medicina, Departamento de Bioquímica, São Paulo SP, Brasil;

${ }^{3}$ Hospital Israelita Albert Einstein, São Paulo SP, Brasil.
}

Correspondence: Luana Mazzacoratti Loeb; Disciplina de Neurociência, Universidade Federal de São Paulo; Rua Pedro de Toledo, 669; 04039-032 São Paulo SP, Brasil; E-mail: luana.loeb@hotmail.com

Conflict of interest: There is no conflict of interest to declare.

Support: CNPq, FAPESP, CAPES, Instituto Nacional de Neurociência Translacional (INNT).

Received 04 April 2018; Received in final form 15 June 2018; Accepted 11 July 2018. 
Botulinum toxin A (BT-A) has been approved for the use in $\mathrm{CM}$ prophylaxis. Botulinum toxin A acts on C-unit, but not on A $\delta$, meningeal nociceptors, inhibiting mechanical nociception to suprathreshold stimuli in peripheral trigeminal neurons, thus decreasing pain. It blocks acetylcholine release at the presynaptic nerve terminal, decreasing neuropeptides and releases other neurotransmitters from sensitized trigeminal endings ${ }^{2,6,8}$.

Low level laser therapy (LLLT) has also been studied in several medical areas, as it is effective for disorders requiring tissue regeneration, pain relief and reduction of inflammation $^{9}$, treating nociceptive, neuropathic ${ }^{10,11}$ and musculoskeletal pain ${ }^{12}$. A meta-analysis has also provided evidence for treatment of neck pain ${ }^{13,14}$. Possible mechanisms explaining the effects of LLLT are signaling molecules (ATP, cyclicAMP, NO) modifying the redox state of cells, free radical production and growth, and transcription factor stimulation ${ }^{15}$.

Although LLLT has been used and extensively studied in the treatment of neck pain, limited information was available regarding migraine prevention. Thus, the development of a protocol for $\mathrm{CM}$ was required. We designed this open label study to test the efficacy of LLLT in CM compared with BT-A, as an additional option for treatment of CM.

\section{METHODS}

The protocol was approved by the Ethics Committee (CAAE: 31148614.0.0000.5505) and all patients gave written consent to this study. The participants' consent was obtained according to the Declaration of Helsinki.
Patients were screened by neurologists from the Sector of Research and Treatment of Headaches of the Neurology/ Neurosurgery Department at the Universidade Federal de São Paulo, Hospital São Paulo, and from other medical centers, over two years. Patients were on stable doses of previously-prescribed prophylaxis medications for three months. Fifty patients were interviewed but only 36 met the criteria for $\mathrm{CM}$ or accepted the randomization process. The 14 excluded patients were unable to follow the LLLT protocol or were unable to fill out the pain diary.

Patients were randomly distributed into two groups, to receive LLLT therapy or BT-A as described in Figure 1. Each group comprised 18 patients. The patients had previously been diagnosed with $\mathrm{CM}$, according to the International Classification of Headache Disorders (International Headache Society, 2014), having presented with headache more than 15 days/month. Although these patients had frequent analgesic use, those overusing medication for headache control were excluded, because they failed items $\mathrm{C}$ and/ or $\mathrm{D}$ of the diagnostic criteria. We also excluded patients with catamenial and tensional headache and patients with fewer than 15 days/month of pain. The patients who agreed to participate in this study remained consistent throughout all processes and no dropouts were registered in either group.

Before the onset of treatment, all patients filled out a headache diary for one month and this period was designated as the baseline phase. When the patients started therapy (BT-A or LLLT), all procedures were carried out by only one professional, to avoid sources of bias.

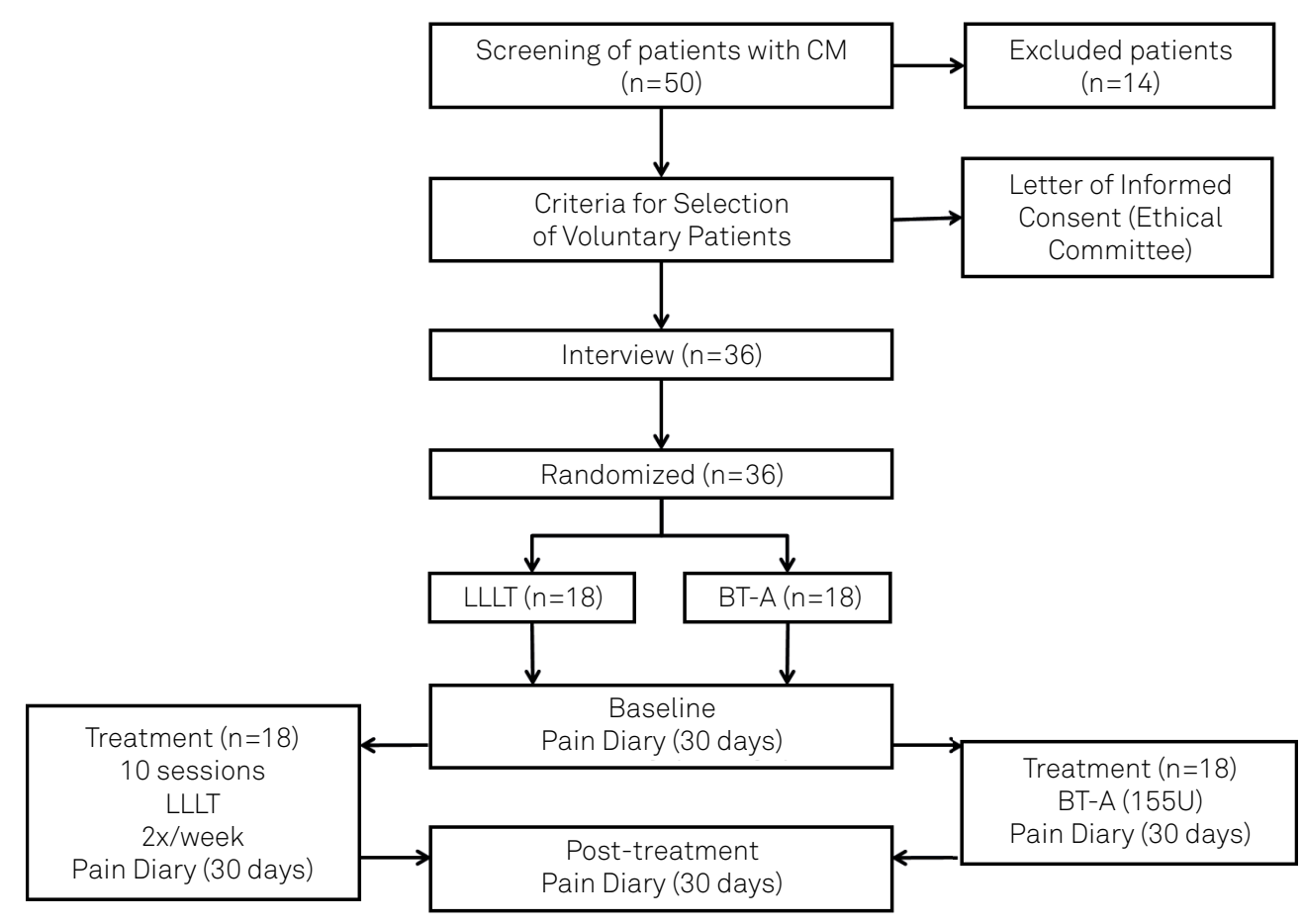

Figure 1. Work Design and flow chart. 


\section{The therapy protocol was as follows:}

$B T-A$ : Botulinum toxin A (200 units) was injected (total of 155 units/31 points) in different muscles such as the corrugator 10 units/ 2 points; procerus 5 units/ 1 point; frontalis 20 units/4 points; temporalis 40 units/8 points; occipital 30 units/ 6 points; cervical paraspinalis 20 units/4 points; trapezium 30 units/6 points, according to the PREEMPT ${ }^{*}$ study $^{16}$. Before treatment (baseline), patients had completed a pain diary (30 days). During the procedure, patients kept the headache diary for another 30 days and, after that, another diary was completed during the posttreatment phase (30 days).

LLLT: Diode laser infrared (Diode Laser II from DMC Equipment Import \& Export Ltd., Brazil) with $100 \mathrm{~mW}$, wavelength $808 \mathrm{~nm}$, dose $120 \mathrm{~J} / \mathrm{cm}^{2}$ during $33 \mathrm{sec} /$ point, with light emitted in a continuous and timely manner, was applied at the same anatomic points used to inject BT-A (Table). Each patient received a total of ten sessions of laser applications, twice a week, for a month. During these procedures, the patients kept a headache diary for three months, starting before treatment onset (baseline) (30 days), during the treatment period (30 days), and another during the post-treatment phase (30 days).

Patients from both groups returned for a follow-up visit and data from the three diaries from each patient were extracted (base line, treatment phase and post-treatment).

The primary endpoint was the number of headache days, comparing the baseline with the post-treatment phase. Medication use data was also collected, and anxiety levels and sleep quality were ascertained by a qualitative score on a scale ranging from $0-10$, as well. These parameters were evaluated using repeated measures ANOVA plus the Bonferroni post-test, Student's $t$ test, and factorial analysis and $p \leq 0.05$ was accepted as significant.

\section{RESULTS}

Comparing the age and sex of patients in the BT-A and LLLT groups displayed no statistical differences, showing

Table. Areas of the LLLT and BT-A applications.

\begin{tabular}{|c|c|}
\hline Head/Neck area & Dose (number of sites ${ }^{a}$ ) \\
\hline Frontalis $^{b}$ & 20 units divided over 4 sites \\
\hline Corrugador ${ }^{b}$ & 10 units divided over 2 sites \\
\hline Procerus ${ }^{b}$ & 5 units divided over 1 site \\
\hline Occipittalis ${ }^{b}$ & 30 units divided over 6 sites \\
\hline Temporalis ${ }^{b}$ & 40 units divided over 8 sites \\
\hline Trapezius $^{b}$ & 30 units divided over 6 sites \\
\hline Cervical paraspinal muscle group ${ }^{b}$ & 20 units divided over 4 sites \\
\hline Total Dose & 155 units divided over 31 sites \\
\hline
\end{tabular}

homogeneity between the two studied groups. The majority of patients were women (two men and 16 women in the BT-A group; four men and 14 women in the LLLT group). Both groups had similar ages (22 to 65 years, mean 42, in the BT-A group; 20 to 62 years, mean 42 in the LLLT group) (age: t test$\left.\mathrm{t}_{34}=0.057 ; \mathrm{p}=0.9550\right)\left(\right.$ sex: $\mathrm{t}$ test $\left.\mathrm{t}_{34}=0.8790 ; \mathrm{p}=0.3855\right)$.

Patients from the BT-A group sometimes complained of worsening of the pain during the first 72 hours after the BT-A application, which decreased on subsequent days. Thirty days after the BT-A application, patients described relaxation of the cervical and facial muscles.

Similarly, during the first four sessions ( $4 \pm 1$ sessions) of laser applications, a few patients described a burning sensation on the trigger points, which disappeared during treatment. This sensation was followed by analgesia and muscle relaxation of the head and face, lasting from two to four hours after laser application. These trigger points were active until the $6^{\text {th }}$ session of LLLT, decreasing after this period as shown in Figure 2.

Collateral effects of both procedures were described in the patient's diary during treatment phase.

Patients from the BT-A group had a mean of 28 pain days/month during the baseline phase, characterizing $\mathrm{CM}$. Analyzing the pain days, the results showed a sharp decrease during the treatment and post-treatment phases, when compared with the baseline phase $(\mathrm{p}<0.001)$. However, no difference was found in the post-treatment phase, when compared with the treatment phase $(\mathrm{p}=1.000)$ (Figure $3, \mathrm{~A})$

In the LLLT group, the number of headache days sharply decreased, when the baseline was compared with the treatment phase $(p<0.001)$ with further decrease in the posttreatment phase $(p<0.001)$, showing a long-lasting effect of LLLT in CM. These patients initially had a mean of 20 headache days/month decreasing to four, and then to two headache days/month (Figure $3 \mathrm{~A}$ ).

Thus, both treatments presented a similar performance concerning headache days $\mathrm{F}(1,499,50,968)=1.531 \mathrm{p}=0.227)$ showing that BT-A and LLLT were equally effective in CM treatment (Figure $3 \mathrm{~A}$ ).

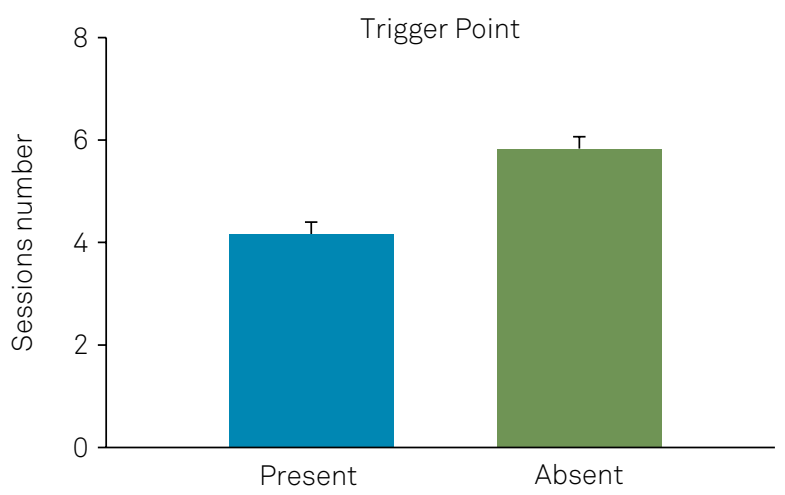

Figure 2. Trigger points. Persistency of trigger points after LLLT application. Bars represent mean \pm standard error before and after $4 \pm 1$ sessions during laser application. $(p=0.001)$. 
During the baseline, patients in both groups referred to major medication intake. This self-medication decreased when comparing the baseline versus the treatment phase, and versus the post-treatment phase $(p<0.001)$ in the BT-A group, showing a decrease in chronic medication intake. However, no difference was found when comparing the treatment with the post-treatment phase $(\mathrm{p}=0.597)$ (Figure 3B).

The number of days using acute medication was also modified in the LLLT group. An important decrease in medication intake was observed in the treatment phase when compared with the baseline $(p<0.001)$, and this decrease continued in the post-treatment phase $(\mathrm{p}<$ 0.001). As well, the medication intake was similar between the BT-A and LLLT groups $(\mathrm{F}(1,446,49,179)=2.341 \mathrm{p}=$ 0.121) (Figure 3B).

Anxiety levels and sleep quality, analyzed using qualitative scores, showed no difference between the groups. Figure 4 shows no difference when anxiety and sleep disorders were compared between the BT-A and LLT groups, but does show an improvement of both parameters during the treatment phase in each group.

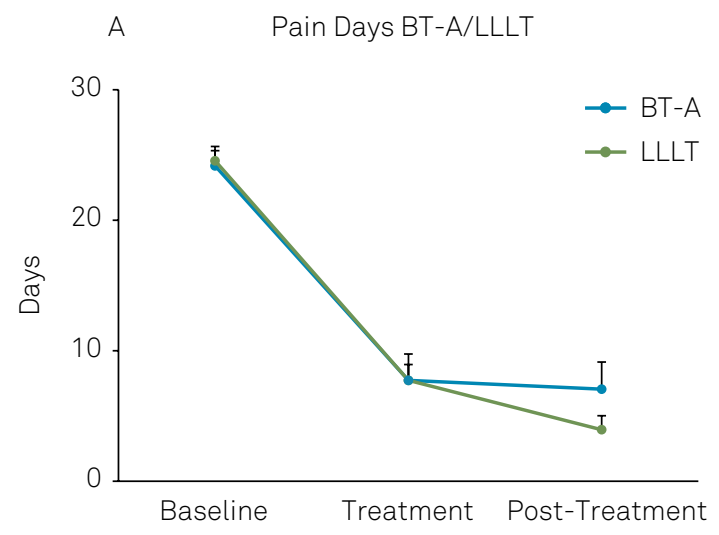

\section{DISCUSSION}

This was a preliminary pilot study exploring the potential of LLLT and BT-A in the treatment in CM. Our results showed that both approaches, BT-A as well as LLLT, reduced headache days and medication intake. In addition, anxiety levels were reduced in the BT-A group, while sleep quality improved in the LLLT group.

Although LLLT is a very promising therapy for pain disorders and a potential candidate for an effective migraine prevention method, its study is very challenging: firstly, because of uncertainty about the mechanisms of action of LLLT at the molecular, cellular and tissue levels. Secondly, there is an extensive number of parameters that can be chosen when designing different LLLT protocols, including: a) application sites in the head and neck; b) the timing, frequency and repetition; c) the wavelength, dose, irradiance; and d) pulsing and polarization. Furthermore, a biphasic dose response should be carefully considered ${ }^{17}$.

Our LLLT protocol, following BT-A PREEMPT injection sites, showed that this could be a feasible strategy. However, a more specific, customized application according to headache location, on a "follow the pain" basis, could also be utilized. In

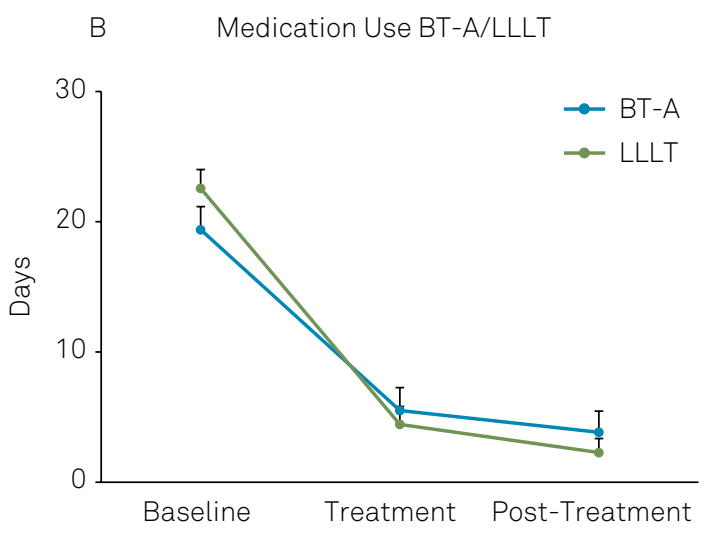

Figure 3. Comparison between pain days (A) and medication use (B). Pain days and medication use were compared during baseline, treatment and post-treatment in BT-A and LLLT groups. No difference was found between BT-A and LLLT treatment.

A

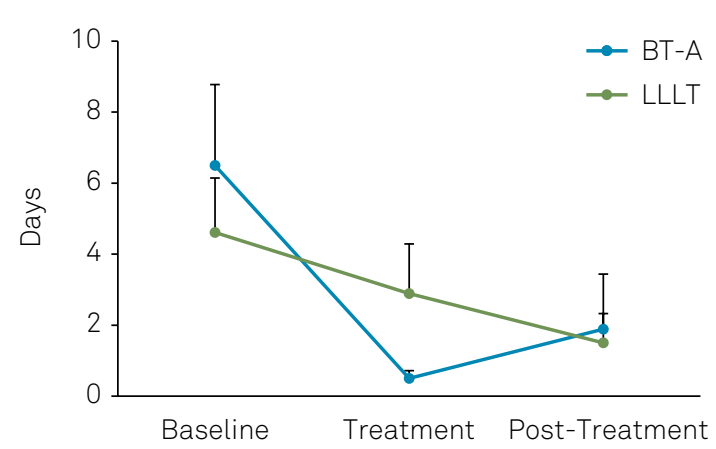

B

Sleep Disorders BT-A/LLT

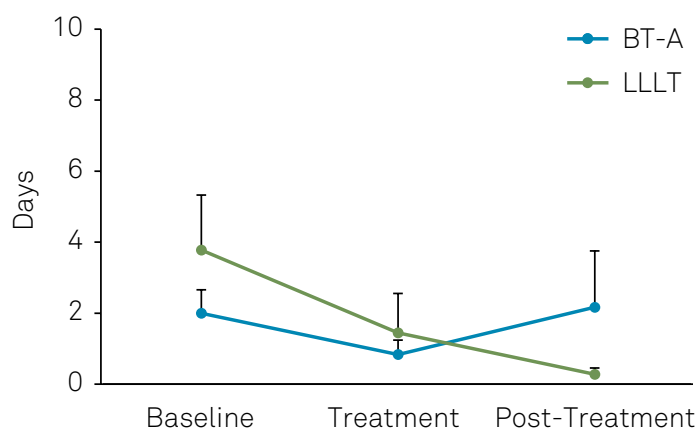

Figure 4. Anxiety and sleep. The presence of jitters (indicating anxiety) and sleep disorder in BT-A and LLLT groups, during baseline, treatment and post-treatment. No difference was found between BT-A and LLLT treatment. 
general, there are four clinical targets for LLLT: a) lymph nodes to reduce edema and inflammation, b) the injury or pain site to promote healing and reduce inflammation, c) nerves to induce analgesia, d) trigger points to reduce tenderness and relax contracted muscle fibers ${ }^{13}$. Our study showed that the 31 points that we employed could be utilized, with good results.

Although both treatments seem effective in reducing CM pain, BT-A is efficient but is expensive, while LLLT might be more cost-effective. Although LLLT requires longer treatment, compliance may increase when the patient finds relief from pain. Thus, BT-A is an invasive and expensive method, while the LLLT is a longer treatment (five weeks), but is cheaper.

Our study has limitations and is presented as an initial approach on how to use LLLT in migraine treatment. It was a head-to-head, open-label comparison, the patients knew which treatment they were receiving, and we could not exclude the placebo effect. Human interaction, a significant aspect affecting placebo response, was higher in the LLLT arm. Double-blind, placebo-controlled trials are needed in future studies to exclude the placebo effect. In addition, the trial period was limited and a longer follow-up could be added in future trials, as repetitive BT-A injections/LLLT applications and cycles could give information on the longterm benefit of LLLT and BT-A treatments. Furthermore, the small sample size in our trial is a significant limitation.

According to our data, LLLT and BT-A may be used in a future approach for the treatment of headache disorders but further studies are necessary to clarify this topic.

\section{References}

1. Peres MF, Sanchez del Rio M, Seabra ML, Tufik S, Abucham $J$, Cipolla-Neto J et al. Hypothalamic involvement in chronic migraine. J Neurol Neurosurg Psychiatry. 2001 Dec;71(6):747-51. https://doi.org/10.1136/jnnp.71.6.747

2. Barbanti P, Egeo G, Fofi L, Aurilia C, Piroso S. Rationale for use of onabotulinum toxin A (BOTOX) in chronic migraine. Neurol Sci. 2015 May;36(1 Suppl 1):29-32. https://doi.org/10.1007/s10072-015-2195-0

3. Burstein R, Noseda R, Borsook D. Migraine: multiple processes, complex pathophysiology. J Neurosci. 2015 Apr;35(17):6619-29. https://doi.org/10.1523/JNEUROSCI.0373-15.2015

4. Suhnan AP, Finch PM, Drummond PD. Hyperacusis in chronic pain: neural interactions between the auditory and nociceptive systems. Int J Audiol. 2017 Nov;56(11):801-9. https://doi.org/10.1080/14992027.2017.1346303

5. Diener HC. Occipital nerve stimulation for chronic migraine: already advised? Cephalalgia. 2012 Oct;32(16):1163-4. https://doi.org/10.1177/0333102412464124

6. Pedraza MI, Cruz C, Ruiz M, López-Mesonero L, Martínez E, Lera M et al. OnabotulinumtoxinA treatment for chronic migraine: experience in 52 patients treated with the PREEMPT paradigm. Springerplus. 2015 Apr;4(1):176-80. https://doi.org/10.1186/s40064-015-0957-z

7. Schulman EA1. Lake AE 3rd, Goadsby PJ, Peterlin BL, Siegel SE, Markley HG, Lipton RB. Defining refractory migraine and refractory chronic migraine: proposed criteria from the Refractory Headache Special Interest Section of the American Headache Society. Headache. 2008 Jun;48(6):77.

8. Garza I, Robertson CE. Critical analysis of the use of onbotulinumtoxin A (botulinum toxin type A in migraine. Neuropsychiatr Dis Treat. 2012;2012(8):35-48.
9. Hashmi JT, Huang YY, Osmani BZ, Sharma SK, Naeser MA, Hamblin MR. Role of low-level laser therapy in neurorehabilitation. PM R. 2010 Dec;2(12 Suppl 2):S292-305. https://doi.org/10.1016/j.pmrj.2010.10.013

10. Nesioonpour S, Mokmeli S, Vojdani S, Mohtadi A, Akhondzadeh $\mathrm{R}$, Behaeen $\mathrm{K}$ et al. The effect of low-level laser on postoperative pain after tibial fracture surgery: a double-blind controlled randomized clinical trial. Anesth Pain Med. 2014 Jun;4(3):e17350. https://doi.org/10.5812/aapm.17350

11. Falaki F, Nejat AH, Dalirsani Z. the effect of low-level laser therapy on trigeminal neuralgia: a review of literature. J Dent Res Dent Clin Dent Prospects. 2014;8(1):1-5.

12. Cotler HB, Chow RT, Hamblin MR, Carroll J. The use of low levels laser therapy (LLLT) for musculoskeletal pain. MOJ Orthop Rheumatol. 2015;2(5):00068. https://doi.org/10.15406/mojor.2015.02.00068

13. Verhagen AP, Schellingerhout JM. Low-level laser therapy for neck pain. Lancet. 2010 Feb;375(9716):721. https://doi.org/10.1016/S0140-6736(10)60296-6

14. Chow RT, Johnson MI, Lopes Martins RA, Bjordal JM. Efficacy of lowlevel laser therapy in the management of neck pain: a systematic review and meta-analysis of randomized placebo or activetreatment controlled trials. Lancet. 2009;374(9705):1897-908.

15. Farivar S, Malekshahabi T, Shiari R. Biological effects of low level laser therapy. J Lasers Med Sci. 2014;5(2):58-62.

16. Allergan. Allergan Patent Notices. Botox®. Madison:Allergan; 2013 Available from: http://www.allergan.com/products/patent_notices, 2013

17. Huang YY, Chen AC, Carroll JD, Hamblin MR and Huang YY. Biphasic dose response in low levels light therapy. 2009;7(4):35883.) https://doi.org/10.2203/dose-response.09-027. Hamblin 